\title{
Wechsler subscale IQ and subtest profile in early treated phenylketonuria
}

\author{
P V Griffiths, C Demellweek, N Fay, P H Robinson, D C Davidson
}

Department of Psychology, University of Stirling and Royal Hospital for Sick Children, Glasgow G3 8SJ, UK P V Griffiths

Roald Dahl EEG Unit, Alder Hey Hospital, Liverpool L12 2AP, UK C Demellweek

Department of Paediatrics, Alder Hey Hospital

D C Davidson

Department of Psychology, University of Glasgow, Glasgow G12 8QF, UK

N Fay

Metabolic Disease Clinic, Royal Hospital for Sick Children, Glasgow

P H Robinson

Correspondence to: Dr P V Griffiths,

Department of Psychology, University of Stirling, Stirling FK9 4LA, UK

email:pvg1@stir.ac.uk

Accepted 3 November 1999

\begin{abstract}
Aim-Mildly depressed IQ is common in treated phenylketonuria. This study explored whether a particular intellectual ability profile typifies early and continuously treated phenylketonuria and whether component skills comprising the IQ relate to socioeconomic and treatment factors.

Methods-IQ scores were collected retrospectively from variants of the "Wechsler intelligence scale for children" performed at age 8 on 57 children with early treated, classic phenylketonuria. The mental ability pattern underlying IQ was investigated by analysing subscale and subtest scores and dietary factors, such as historical phenylalanine blood concentrations.

Results-The children's mean full scale IQ of 91.11 was significantly below the healthy population norm. There was a significant discrepancy between their mean verbal IQ (94.65) and mean performance IQ (89.42), suggestive of a spatial deficit, but the data did not support a biochemical or sociological explanation. Individual Wechsler subtests had no distinctive pattern. Phenylalanine control at age 2 was predictive of overall IQ. At this age, children with annual median phenylalanine $<360 \mu \mathrm{mol} / \mathrm{litre}$ (recommended UK upper limit) had a mean IQ 10 points higher than those above.

Conclusions-Early and continuous treatment of phenylketonuria does not necessarily lead to normalisation of overall IQ. Verbal intelligence in the primary school years appears to normalise if blood phenylalanine is maintained below $360 \mu \mathrm{mol} / \mathrm{litre}$ in infancy, but spatial intelligence may remain poor. However, the discrepancy in skill development is not the result of social status or treatment variables. Perhaps weak spatial intelligence is an ancillary effect of a protective rearing style occasioned by the dietary treatment regimen.

(Arch Dis Child 2000;82:209-215)
\end{abstract}

Keywords: phenylketonuria; intelligence quotient; dietary treatment; policy

Since the initiation in the 1960 s of mass screening for phenylketonuria (McKusick 261600), treatment outcome during the school age period has been assessed principally by the "Wechsler intelligence scale for children" (WISC). ${ }^{1}$ In general, outcome studies have related Wechsler IQ to independent variables such as severity, age of commencement of dietary phenylalanine restriction, phenylalanine range during treatment, and age of dietary discontinuation. Most studies have selected the overall or full scale IQ as the dependent variable, this paradigm typifying the approach taken by national collaborative studies in the UK and the USA. ${ }^{2}$ Although the full scale IQ provides a convenient summary of intellectual development, it obscures the richness of information about individual or group profiles of mental skill inherent in WISC assessments. To our knowledge, among studies of treatment factors in phenylketonuria, there are no reports concerning the 10 subtest scores on which full scale and subscale IQs are based, despite their necessarily having been collected in the course of testing. Thus, the question of whether a particular WISC subtest profile characterises treated phenylketonuria has not been explored.

Verbal and performance IQ subscale scores on the WISC have been reported occasionally and the findings of higher verbal than performance IQ scores suggest that visuospatial cognitive functioning might be poorer than verbal linguistic abilities. ${ }^{45} \mathrm{~A}$ more frequently documented finding is that full scale IQ falls below that of siblings, ${ }^{6}$ parents, ${ }^{7}$ and the population norm. ${ }^{8}$ In relation to the verbal to performance IQ discrepancy and Wechsler profile issue, this begs the question whether lowered IQ is the result of uniform depression of subtest scores or whether specific cognitive skills contribute more than others to the deficiency. A further reason for exploring the Wechsler profile is to appraise whether the mild hyperphenylalaninaemia typical of the treated condition might be responsible for imbalances in cognitive development. The history of phenylketonuria research is punctuated with reports suggesting that specific skill deficits might accompany treatment conducted according to the standards of the day ${ }^{10}$; however, despite the WISC being the most common measure of cognition during and after dietary treatment, it is a paradox that the WISC subtest profile has not been examined for strengths and weaknesses and how these might reflect dietary phenylalanine control.

The aim of our study was to fill this gap in the knowledge base by retrospectively gathering data from Wechsler tests given to treated children with phenylketonuria and analysing scores not only at the overall IQ level but also at the subscale (verbal and performance IQs) and subtest levels. Five verbal linguistic subtests underlie the verbal IQ. With the psychological constructs they measure in brackets, they are: 
information (factual knowledge), similarities (verbal concept formation), arithmetic (mental arithmetic), vocabulary (word definitions), and comprehension (social understanding). Five visuospatial subtests underlie the performance IQ: picture completion (perception of visual detail), picture arrangement (logical reasoning), block design (visual analysis), object assembly (part/whole construction), and coding (symbol manipulation).

The patient sample for our study was compiled to represent the phenylketonuria population currently of paramount clinical interest; namely, the early and continuously treated classic group. Although in all cases treatment had been continuous until the time of testing at 8 years of age, lifetime control of dietary phenylalanine intake varied, thereby allowing investigation of associations between historical phenylalanine concentrations and WISC scores. Furthermore, pretest phenylalanine control could be categorised in terms of its conformity to current UK guidelines, thus enabling the exploration of treatment compliance effects on Wechsler profiles.

\section{Methods}

PATIENT SAMPLE

The sample consisted of 57 children ( 27 boys and 30 girls), 32 of whom were derived from the Liverpool phenylketonuria register and 25 from the Glasgow phenylketonuria register. Only data from children with classic or type 1 phenylketonuria and in whom dietary restriction of phenylalanine began before the 8th week of life were entered into the analysis. Classic phenylketonuria was operationally defined as peak phenylalanine concentrations in blood greater than $1200 \mu \mathrm{mol} /$ litre before treatment. ${ }^{11}$ Data from children with known neurological or psychiatric comorbidity were excluded. When tested for IQ, each child was as near as possible to his or her 8th birthday, the mean chronological age at test of the sample being 8.14 years $(\mathrm{SD}, 0.30)$.

IQ TESTS

In each case, the most recent revision of the WISC current at the time of testing was used to measure IQ. Four variants were administered: the original WISC, ${ }^{1}$ the "Wechsler intelligence scale for children revised" (WISC-R), ${ }^{12}$ the "Wechsler intelligence scale for children revised, Scottish edition" (WISC-RS), ${ }^{13}$ and the "Wechsler intelligence scale for children third UK edition" (WISC-3UK). ${ }^{14}$ Eleven children received the WISC, 32 the WISC-R, one the WISC-RS, and 13 the WISC-3UK. Full scale, verbal, and performance IQs, and subtest scaled scores were collated.

DESIGN, PROCEDURE, AND ANALYSIS

Our study was a retrospective analysis of IQ outcome in relation to treatment factors and social class. Testing was conducted close to the children's 8th birthdays, this timing complying with that required of regional centres by the protocol of the UK national collaborative study of phenylketonuria. ${ }^{15}$ Tests were administered by clinical and educational psychologists be- tween the years 1972 and 1998 (median, 1986). Independent variables were peak pretreatment phenylalanine concentration (the highest diagnostic reading in $\mu \mathrm{mol} /$ litre), age treatment started (in days postpartum), and indices of dietary control, these being annual median phenylalanine concentrations ( $\mu \mathrm{mol} /$ litre) during the first 8 years of life. ${ }^{16}$ Social class, operationally defined in terms of the income of the chief earner in the family, was also included as an independent variable and measured on a scale of 1 to 7 , with 1 representing professional employment and 7 unemployment. ${ }^{17}$ Dependent variables were WISC full scale IQ, verbal subscale IQ, performance subscale IQ, and subtest scaled scores. Results from the various revisions of the WISC are standardised on age stratified child populations, thereby permitting norm referenced comparisons. Full scale IQ was corrected for upward drift in population norms over time, ${ }^{18}$ using the method described by Smith et al. ${ }^{19}$

Regression analyses were performed on within group associations between treatment factors and IQs at age 8. As a test of the UK recommendation for dietary treatment that blood phenylalanine concentrations be kept below $360 \mu \mathrm{mol} /$ litre in the preschool years, ${ }^{20}{ }^{21}$ the sample was divided into two groups according to whether individual control in the 2nd year of life was above or below the cut off point of $360 \mu \mathrm{mol} /$ litre. The age at which the sample was split was determined by stepwise dropout regression. The dataset was analysed by MiniTab version 10.5 (statistical package for the Macintosh computer). Standard deviations and mean values are given, two tailed tests were used throughout, and $\alpha$ was set at 0.05 or less.

\section{Results}

TREATMENT VARIABLES AND SOCIAL CLASS

Peak diagnostic phenylalanine concentrations in the 57 children before treatment ranged from 1200 to $5400 \mu \mathrm{mol} /$ litre (mean, 2557; SD, 1047) and the day of life that treatment began ranged from 4 to 55 (mean, 17.15; SD, 8.94). Yearly indices of dietary control (IDCs) for individual children until age 8 were averaged across the group. Figure 1 shows the resulting curve. One way analysis of variance (ANOVA) confirmed the significance of the rise in mean IDC with increasing age $(\mathrm{F}=4.27$; degrees of freedom (df), 7/448; $\mathrm{p}<0.001)$. Average lifetime phenylalanine as measured by the mean annual IDC was $466 \mu \mathrm{mol} /$ litre (SD, 154). Mean social class on the seven point scale was 4.56 (SD, 1.56).

IQ OUTCOME AND POPULATION NORMS

Full scale, verbal, and performance IQ scores were all normally distributed (AndersonDarling test). The uncorrected mean full scale IQ was 91.11 (SD, 14.01), the verbal IQ mean was 94.65 (SD, 13.99), and the performance IQ mean was 89.42 (SD, 14.69). The discrepancy between the verbal and performance IQS was significant $(t=3.25 ; \mathrm{df}, 56 ; \mathrm{p}<0.01$, related). The uncorrected mean full scale IQ 


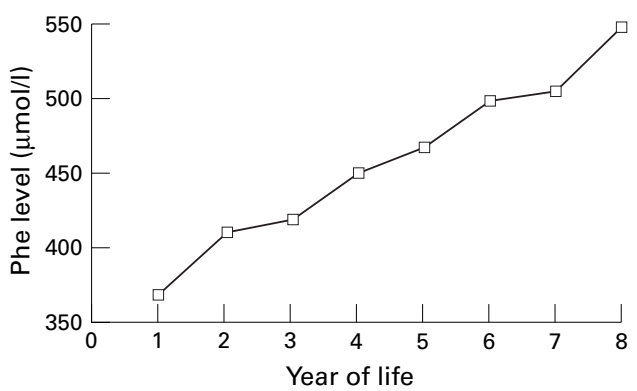

Figure 1 Yearly averages in umol/litre of median phenylalanine concentrations between ages 1 and 8 for entire sample $(n=57)$.

was significantly below the population norm $(Z=-4.48 ; p<0.001)$, as was the mean verbal IQ $(Z=-2.69 ; \mathrm{p}<0.01)$ and the mean performance IQ $(Z=-5.33$; $p<0.001)$. After correcting the WISC and WISC-R scores for temporal drift in population norms, the mean full scale IQ fell to 85.82 (SD, 13.93). The difference between the uncorrected and corrected full scale IQ figures was significant $(t=12.29$; df, 56; $\mathrm{p}<0.001$, related).

TREATMENT FACTORS, SOCIAL CLASS, AND FULL SCALE IQ

In view of the significant difference between the uncorrected and corrected full scale IQ distributions, the corrected full scale IQ was used as the central outcome variable. When the corrected full scale IQ was regressed on peak phenylalanine before treatment, day of treatment commencement, mean lifetime phenylalanine, and social class, the latter combination was found to predict IQ outcome reliably $(\mathrm{F}=4.65 ; \mathrm{df}, 4 / 52 ; \mathrm{p}<0.01)$. However, stepwise dropout regression showed that only social class and mean lifetime phenylalanine contributed significantly to the effect. Simple correlation revealed significant negative associations between social class and corrected full scale IQ $(r=-0.37 ; \mathrm{df}, 55 ; \mathrm{p}<0.01)$, and mean lifetime phenylalanine and corrected full scale IQ $(r=-0.35 ; \mathrm{df}, 55 ; \mathrm{p}<0.01)$, the implication being that the higher the social class and the lower the lifetime phenylalanine, the higher the corrected full scale IQ. Social class and mean lifetime phenylalanine themselves correlated significantly $(r=0.28$; df, 55 ; $\mathrm{p}<0.05)$, the coefficient implying that the higher the social class (or lesser the scale value) the lower was the average phenylalanine concentration over the first 8 years of life. To investigate whether mean lifetime phenylalanine alone predicted the corrected full scale
IQ, a partial correlation analysis was conducted with social class controlled. ${ }^{22}$ This confirmed that, irrespective of the influence of social class, mean lifetime phenylalanine predicted corrected full scale IQ at beyond the $5 \%$ chance level $(Z=-2.04 ; \mathrm{p}<0.05)$.

The question then arose as to which of the eight IDCs making up the lifetime phenylalanine average significantly contributed to the corrected full scale IQ effect. To answer this, each IDC distribution from year 1 to year 8 along with social class, start day, and peak phenylalanine was entered into a stepwise dropout analysis. The result was that social class predicted corrected full scale IQ reliably, as expected. However, only the IDC distribution at year 2 remained as consistently having a significant influence on later IQ. With social class controlled, partial correlation revealed that phenylalanine concentrations at year 2 remained significantly predictive of corrected full scale IQ $(Z=-2.18 ; \mathrm{p}<0.05)$.

TREATMENT POLICY AND FULL SCALE IQ

In the light of the finding that the association between corrected full scale IQ and lifetime phenylalanine control was principally the result of variance in blood phenylalanine in the 2 nd year of life, the sample was divided according to whether individual children's concentrations fell above or below $360 \mu \mathrm{mol} /$ litre at this age, $360 \mu \mathrm{mol} /$ litre being the upper limit of the treatment target range currently recommended in the UK for the preschool period. ${ }^{20}$ This procedure yielded two subgroups for comparison of IQ, one containing 29 children whose individual IDCs at year 2 were less than $360 \mu \mathrm{mol} / \mathrm{litre}$, and one containing 28 children whose IDCs were above. The average phenylalanine concentrations for the low and high phenylalanine group were 287 (SD, 66) and 539 (SD, 127) $\mu \mathrm{mol} /$ litre, respectively. Because their phenylalanine distributions did not overlap, this difference was significant $(t=9.32$; df, 55; $\mathrm{p}<0.001$, unrelated). Furthermore, only the phenylalanine concentration differentiated the groups who were otherwise matched on chronological age $(\mathrm{t}=0.43)$, peak pretreatment phenylalanine $(\mathrm{t}=1.84)$, day of starting treatment $(\mathrm{t}=0.55)$, and social class $(\mathrm{t}=0.73)$ (all t ratios: df, 55; p, not significant (NS)) (table 1).

The mean corrected full scale IQ of the low phenylalanine group was 10 points higher than that of the high phenylalanine group (table 1), this difference being significant $(t=2.81$; df, $55 ; \mathrm{p}<0.01)$. Likewise, when uncorrected full

Table 1 Subgroup variable scores for low and high phenylalanine groups

\begin{tabular}{lllllll}
\hline Group & Age (years) & $\begin{array}{l}\text { Peak } \\
\text { phenylalanine } \\
(\mu m o l / l)\end{array}$ & Start day & $\begin{array}{l}\text { Social class } \\
(1-7)\end{array}$ & $c F S I Q$ & FSIQ \\
\hline $\begin{array}{l}\text { Low phenylalanine } \\
(\mathrm{n}=29)\end{array}$ & $8.12(0.3)$ & $2311(1070)$ & $17.8(11.3)$ & $4.41(1.62)$ & $90.6^{\star}(12.2)$ & $95.07^{\star \star}(13.47)$ \\
$\begin{array}{c}\text { High phenylalanine } \\
(\mathrm{n}=28)\end{array}$ & $8.16(0.3)$ & $2811(977)$ & $16.5(5.7)$ & $4.71(1.51)$ & $80.8^{\star}(14.0)$ & $87.00^{\star \star}(13.58)$ \\
\hline
\end{tabular}

Values are mean (SD).

The low phenylalanine group (individual indices of dietary control (IDCs) $<360 \mu \mathrm{mol} /$ litre at age 2 ) and the high phenylalanine group (individual IDCs $>360 \mu \mathrm{mol} /$ litre at age 2) were matched for age at test, peak pretreatment phenylalanine, day of treatment commencement, and social class, but differed significantly in both corrected full scale IQ (cFSIQ) and uncorrected FSIQ. ${ }^{\star} \mathrm{p}<0.01 ;{ }^{\star \star} \mathrm{p}<0.05$ 
Table 2 Wechsler verbal IQ and performance IQ scores for low and high phenylalanine groups

\begin{tabular}{lrl}
\hline Group & Verbal IQ & Performance IQ \\
\hline Low $(\mathrm{n}=29)$ & $100.17(13.40)$ & $91.76(14.71)$ \\
High $(\mathrm{n}=28)$ & $88.93(12.37)$ & $87.00(14.53)$ \\
\hline
\end{tabular}

Values are mean (SD).

ANOVA revealed significant main and interaction effects.

scale IQs were analysed, the low phenylalanine group remained superior $(t=2.25$; df, 55; $\mathrm{p}<0.05)$.

TREATMENT POLICY AND SUBSCALE IQ

Table 2 shows verbal and performance IQ scores for the low and high phenylalanine groups. As can be seen, the mean verbal IQ for the low phenylalanine group was normal. Mixed design ANOVA of verbal and performance IQ scores between the low and high phenylalanine groups revealed significant main effects for phenylalanine control $(\mathrm{F}=5.87$; df, $1 / 55 ; \mathrm{p}<0.05)$ and subscale $(\mathrm{F}=10.92 ; \mathrm{df}$, $1 / 55 ; \mathrm{p}<0.01)$ and a significant interaction $(\mathrm{F}=4.29 ; \mathrm{df}, 1 / 55 ; \mathrm{p}<0.05)$. Post hoc paired mean comparisons (Scheffe) confirmed that the difference between the verbal and performance IQs of the low phenylalanine group was significant $(\mathrm{p}<0.05)$ and that the verbal IQ of the low phenylalanine group was significantly above that of the high phenylalanine group. Other comparisons were non-significant. When the verbal to performance IQ difference within the low and high phenylalanine groups was regressed separately on severity (peak phenylalanine), treatment factors (start day, IDC at year 2, and lifetime phenylalanine), and social class, no significant associations emerged.

SUBSCALE IQ, SEX, SOCIAL CLASS, AND TREATMENT FACTORS

Although the discrepancy for the entire sample between the verbal IQ mean of 94.65 and the performance IQ mean of 89.42 was significant

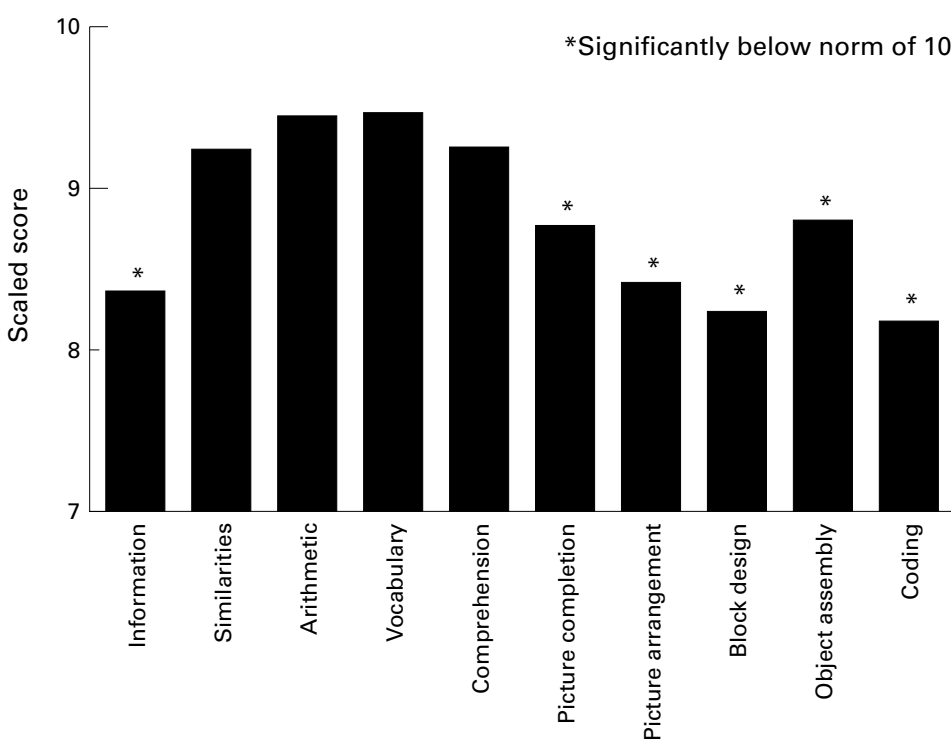

Figure 2 Mean Wechsler subtest score profile for entire sample. Only similarities, arithmetic, vocabulary, and comprehension were not significantly below the population mean of 10 .
$(\mathrm{F}=10.74 ; \mathrm{df}, 1 / 55 ; \mathrm{p}<0.01)$, sex effects were absent. The 27 boys had mean verbal and performance IQ scores of 95.11 (SD, 15.61) and 88.48 (SD, 15.03), respectively; the 30 girls had mean verbal and performance IQ scores of 94.23 (SD, 12.61) and 90.27 (SD, 14.58), respectively. However, neither the sex factor $(\mathrm{F}=0.017 ; \mathrm{df}, 1 / 55 ; \mathrm{p}, \mathrm{NS})$ nor the interaction between sex and subscale was significant $(F=0.68 ; d f, 1 / 55 ; p, N S)$. To assess whether the verbal and performance IQ imbalance in cognition could be attributed to social class or treatment factors, individual verbal to performance IQ differences for all children were regressed on social class, peak phenylalanine, start day, and mean lifetime phenylalanine. Neither the multiple regression equation nor any of the individual factors were found to be significantly predictive, suggesting that the inconsistency in the subscales of the Wechsler tests was associated with characteristics other than treatment history and social background. This view was confirmed by simple correlation and stepwise dropout regression using annual mean IDCs as predictors. Verbal IQ correlated negatively and significantly with preschool phenylalanine $(r=-0.29$; df, 55; $\mathrm{p}<0.05)$, but performance IQ was not associated with phenylalanine at any age.

\section{SUBTEST PROFILE}

Figure 2 shows the profile of the individual subtest means of the Wechsler tests. These are age corrected and standardised on a scale with a population mean of 10 and a standard deviation of 3. The supplementary "digit span" and "mazes" subtests were not routinely administered and hence do not appear. Despite the mean verbal and performance IQs being significantly inferior to the population norm, not all the subtests echoed this pattern. $Z$ tests for sample to population comparisons showed the following subtest means to be significantly below the population average:

information $(Z=-4.15 ; \mathrm{p}<0.001)$

picture completion $(Z=-3.10 ; p<0.01)$

picture arrangement $(Z=-3.98 ; p<0.001)$

block design $(Z=-4.45 ; \mathrm{p}<0.001)$

object assembly $(Z=-3.05 ; \mathrm{p}<0.01)$

coding $(Z=-4.58 ; \mathrm{p}<0.001)$.

The remaining subtests-similarities, arithmetic, vocabulary, and comprehension-did not differ significantly from age expectations. Thus, all the performance scale subtests fell significantly below the population norm, but among the verbal scale subtests only information was significantly depressed. Multiple and stepwise regression analysis failed to show any significant associations between treatment factors and individual subtests except for information, which was predicted by IDC at year $2(\mathrm{~F}=10.41 ; \mathrm{df}, 1 / 55 ; \mathrm{p}<0.01)$.

PHENYLALANINE CONTROL AND HISTORICAL TREATMENT PERIOD

Because the sample comprised patients treated over a long period in the history of phenylketonuria, the question of whether phenylalanine control in the 1960s and 1970s might have been less strict than in the 1980s was 
investigated empirically. Although the lifetime phenylalanine mean of $500 \mu \mathrm{mol} /$ litre (SD, 144) for the 28 patients first treated between 1964 and 1977 was higher than that of $433 \mu \mathrm{mol} /$ litre (SD, 159) for the 29 patients first treated between 1978 and 1990, the difference was not significant $(\mathrm{t}=1.67$; $\mathrm{df}, 55$; $\mathrm{p}, \mathrm{NS}$ ).

\section{Discussion}

In summary, the principal findings were:

- phenylalanine control worsened progressively with age

- no evidence was found for more stringent phenylalanine control in the 1980s than in the 1970 s

- average full scale IQ fell significantly short of age expectation, irrespective of correction for normative drift over time

- sex had no effect on overall or subscale IQ

- social class correlated significantly with lifetime phenylalanine and full scale IQ

- when social class effects were controlled, lifetime phenylalanine, and especially phenylalanine concentrations at age 2, predicted full scale IQ

- children with average phenylalanine concentrations below $360 \mu \mathrm{mol} /$ litre at age 2 achieved a mean full scale IQ 10 points higher at age 8 than those with phenylalanine concentrations above $360 \mu \mathrm{mol} /$ litre at the same age

- verbal IQ was significantly superior to performance IQ but the discrepancy was not accounted for by historical phenylalanine concentrations

- early phenylalanine control below $360 \mu \mathrm{mol} /$ litre was associated with normal verbal IQ but significantly depressed performance IQ

- compared with population standards, the Wechsler subtest profile was characterised by abnormally low scores on all performance subscale measures, whereas the verbal subscale measures, with the exception of information, were within normal limits.

Rigid inclusion criteria ensured the sample tested was uncontaminated by variables such as lateness of treatment or mild hyperphenylalaninaemia. Thus, there is no reason to believe that the children tested were unrepresentative of the wider early treated, classic phenylketonuria population at age 8 and that the above results suffer from sample bias.

Between birth and age 8, loss of phenylalanine control was incremental and relentless (fig 1), mean IDCs mirroring those reported by Weglage et al for a similar early treated group. ${ }^{23}$ Year by year increases in phenylalanine concentrations in treated phenylketonuria have been reported elsewhere ${ }^{8}$; however, the notion that clinical practice has become more stringent over the course of the past 25 years was not supported by the dataset.

The finding that phenylalanine control at age 2 was the most powerful predictor of later IQ adds weight to the view that phenylalanine affects IQ most adversely in the early years of life and emphasises the importance of good

\section{Key messages}

- The lower than average IQ often found in treated phenylketonuria might be caused in part by specific weakness in spatial ability

- Conformity to current UK recommendations for phenylalanine concentrations at least in infancy is associated with normal verbal IQ in later childhood

- Better verbal than spatial intelligence in treated phenylketonuria might not be a function of dietary treatment factors or social status

dietary control in infancy. Independent national studies have concluded that phenylalanine only affects IQ until age $5,{ }^{24}{ }^{25}$ the implication being that the influence of raised phenylalanine concentrations diminishes over the preschool period. In support of this theory, for the sample as a whole, mean phenylalanine between birth and age 5 correlated significantly and negatively with uncorrected full scale IQ at age $8(r=-0.26$; df, 55; p < 0.05), whereas the association between mean phenylalanine from age 6 to 8 and full scale IQ was random. This pattern also obtained for corrected full scale IQ.

We found the mean uncorrected full scale IQ to be 91.11 , which agrees with earlier ${ }^{26}$ and more recent findings, ${ }^{23}$ and is not only significantly below the norm for the healthy population but is also below the figure of 94 for a sample of 14 year old treated patients. ${ }^{8}$ However, although there is converging evidence that full scale IQ in early treated phenylketonuria falls below age standards, the data in table 1 confirm that maintaining phenylalanine below the upper limit recommended in the $\mathrm{UK}$ in infancy can mitigate this effect. The data in table 2 further suggest that verbal IQ emerges at age 8 entirely unimpaired when treatment follows the current UK policy of keeping phenylalanine below $360 \mu \mathrm{mol} /$ litre in early childhood.

The verbal to performance IQ discrepancy in favour of higher verbal skills concurs with previous findings. ${ }^{45}$ The significant difference in subscale scores is unlikely to have been an artefact of fluctuating test norms over time. WISC data summarised by Flynn consistently show rises in performance IQ compared with verbal IQ during the $1970 \mathrm{~s}$ and $1980 \mathrm{~s}^{27}$ whereas in our study the direction of the subscale difference was the reverse, despite the median test date being 1986.

On the basis of data obtained from neuropsychological tests, separate authors have queried whether a specific visuospatial deficit might characterise treated phenylketonuria. ${ }^{28}{ }^{29}$ The analysis of the subscale scores (table 2) leads to a more qualified view. First, the significant verbal to performance IQ imbalance, although detectable in the entire sample, was principally the result of the subgroup whose early phenylalanine control stayed within recommended UK limits in early life. Second, 
there was no evidence from regression analyses that this test pattern could be attributed either to biochemical factors, at least in terms of lifetime phenylalanine exposure, or to social factors such as socioeconomic status. Furthermore, although a neurotoxic explanation is appealing on the grounds of performance IQ being a more sensitive index of brain damage than verbal IQ, and performance IQ measures being more representative of the fluid intelligence and executive functions that some authors believe are particularly vulnerable to raised phenylalanine concentrations, ${ }^{30}{ }^{31}$ the results in table 2 contradict this view. If neurotoxic factors had been operating, a greater discrepancy would have been expected in the high rather than the low phenylalanine group, whereas the opposite was found to be the case.

The analyses of the subtest profile and verbal to performance IQ discrepancy were largely complementary, the uniformly depressed performance subtests indicating widespread difficulty with visuospatial reasoning, rather than a subtle pattern of discrete cognitive strength and weakness. Therefore, the evidence does not point to a distinctive signature of WISC subtest scores in treated phenylketonuria akin to that found-for example, in developmental dyslexia. ${ }^{32}$ However, the low information score conflicts with the view that spatial skills are exclusively weak and raises the possibility that factual knowledge also is under developed.

Why then should verbal skill, with the exception of factual knowledge, be superior to spatial skill in treated phenylketonuria, especially in patients whose early phenylalanine control was optimal by nationally recommended standards? Our data support neither a neuropsychological explanation based on raised phenylalanine concentrations nor a sociological explanation based on social class. A third possibility is a developmental account based on idiosyncratic child rearing practices being potentiated by the rigours of implementing the restricted diet. The data show that, although high verbal IQ was associated with good early phenylalanine control, overall, the children were spatially weak irrespective of historical phenylalanine concentrations. This result raises the possibility of spatial exploration being hindered in early treated phenylketonuria, perhaps as a consequence of parental concern over adherence to the diet generalising to an over protective rearing style. Higher than average protectiveness and restrictiveness in carers of children with phenylketonuria have been reported elsewhere. ${ }^{33}{ }^{34}$ The low performance IQ finding, when considered in the light of these psychosocial characteristics, prompts the speculative hypothesis (an issue for further research) that families of early treated children with phenylketonuria, in their anxiety to conform to diet, might inadvertently shield their children from experiential diversity tothepointofimpedingdevelopmentinthevisuospatial domain of cognition. Although specific spatial impairment is a feature of disorders where there is poor physical mobility, ${ }^{35}$ it is not known whether spatial under functioning can arise from overprotection. Reliable methodologies now exist for quantifying overprotection, ${ }^{36}$ and we plan to explore the association between this aspect of parenting and the spatial skill of children with phenylketonuria in a subsequent study.

We are grateful for the help provided at various stages of this project by Dr R Logan and his staff, Miss H Livingstone and Miss K Newlands at the Royal Hospital for Sick Children, Glasgow; Dr I Smith and her staff at the Institute of Child Health, gow; Dr I Smith and her staff at the Institute of Child Health, and SHS International (Liverpool, UK).

1 Wechsler D. Wechsler intelligence scale for children. New York: Psychological Corporation, 1949.

2 Smith I, Beasley MG, Ades AE. Intelligence and quality of dietary treatment in phenylketonuria. Arch Dis Child 1990; 65:472-8.

3 Dobson JC, Williamson ML, Azen C, Koch R. Intellectual assessment of 111 four-year-old children with phenylketonuria. Pediatrics 1997;60:822-7.

4 Koff E, Boyle P, Pueschel SM. Perceptual-motor functioning in children with phenylketonuria. Am F Dis Child 1977; 131:1084-7.

5 Sonneville LMJ de, Schmidt E, Michel U, Batzler U. Preliminary neuropsychological test results. Eur $\mathcal{F}$ Pediatr 1990;149(suppl 1):S39-44.

6 Williamson ML, Koch R, Azen C, Chang C. Correlates of intelligence test results in treated phenylketonuric children. Pediatrics 1981;68:161-7.

7 Berry HK, O'Grady DJ, Perlmutter LJ, Boffinger MK. Intellectual development and academic achievement of children treated early for phenylketonuria. Dev Med Child Neurol 1979;21:311-20.

8 Beasley MG, Costello PM, Smith I. Outcome of treatment in young adults with phenylketonuria detected by routine neonatal screening between 1964 and 1971. Q f Med 1994;87:155-60.

9 Welsh MC, Pennington BF, Ozonoff S, Rouse B, McCabe ERB. Neuropsychology of early-treated phenylketonuria: specific executive function deficit. Child Dev 1990;61: 1697-713.

10 Diamond A. Phenylalanine levels of 6-10 mg/dl may not be as benign as once thought. Acta Paediatr 1994;83(suppl 407):89-91.

11 Guttler F. Hyperphenylalaninaemia: diagnosis and classification of the various types of phenylalanine deficiency in childhood. Acta Paediatr 1980;280(suppl):S1-80.

12 Wechsler D. Wechsler intelligence scale for children - revised UK edition. Windsor: NFER-Nelson, 1976.

3 Scottish Council for Research in Education. Wechsler intelligence scale for children-revised, Scottish standardization. Sidcup: Psychological Corporation, 1987.

14 Wechsler D. Wechsler intelligence scale for children-third edition UK. Sidcup: Psychological Corporation, 1992.

15 Smith I, Beasley M. Intelligence and behaviour in children with early-treated phenylketonuria. Eur $\mathcal{F}$ Clin Nutr with early-treat

16 Rupp A, Burgard P. Comparison of different indices of dietary control in phenylketonuria. Acta Paediatr 1995;84: $521-7$.

17 Office of Population Censuses and Surveys. Classification of occupations. London: HMSO, 1980.

18 Flynn JR. Massive IQ gains in 14 nations: what IQ tests really measure. Psychol Bull 1987;95:29-51.

19 Smith I, Beasley MG, Ades AE. Effect on intelligence of relaxing the low phenylalanine diet in phenylketonuria. Arch Dis Child 1990;65:311-16.

20 Medical Research Council. Recommendations on the dietary management of phenylketonuria. Arch Dis Child 1993;68:426-7.

21 National Society for Phenylketonuria. Management of PKU: a consensus document. Gateshead: NSPKU/SHS International, 1999.

22 Hays WL. Other topics in regression and correlation. In: Statistics. London: Holt, Rinehart, and Winston, 1970: 574-7.

23 Weglage J, Funders B, Wilken B, Schubert D, Ullrich K. School performance and intellectual outcome in adolescents with phenylketonuria. Acta Paediatr 1993;81:582-6.

24 Azen CG, Koch R, Friedman EG. Intellectual development in 12-year-old children treated for phenylketonuria. $A m \mathcal{F}$ Dis Child 1991;145:35-9.

25 Burgard P, Rupp A, Konecki DS, Trefz FK, Schmidt H, Lichter-Konecki U. Phenylalanine hydroxylase genotypes, predicted residual enzyme activity and phenotypic parameters of diagnosis and treatment of phenylketonuria. Eur $\mathcal{F}$ Pediatr 1996;155(suppl 1):S11-15.

26 Smith I, Lobascher M, Wolff OH. Factors influencing outcome in early-treated phenylketonuria. In: Seakins JWT, ed. Treatment of inborn errors of metabolism. Edinburgh: Churchill, 1973:41-9.

27 Flynn JR WAIS-III and WISC-III IQ gains in the United States from 1972 to 1995: how to compensate for obsolete norms. Percept Mot Skills 1998;86:1231-9.

28 Brunner RL, Berch DB, Berry H. Phenylketonuria and complex spatial vizualization. Dev Med Child Neurol 1987; 29:460-8. 
29 Pennington BF, van Doornick WJ, McCabe LL, McCabe ERB. Neuropsychological deficits in early treated phe-

30 Sattler JM. Organic brain damage. In: Assessment of children's intelligence. Philadelphia: Saunders, 1974:298-9.

31 Welsh MC. A prefrontal dysfunction model of early-treated phenylketonuria. Eur f Pediatr 1996;155(suppl 1):S87-9.

32 Huelsman CB. The WISC subtest syndrome for disabled readers. Percept Mot Skills 1970;30:535-50.

33 Hendrikx MMT, Vanderschot LWA, Slijper FME, Huisman $\mathrm{J}$, Kalverboer AF. Phenylketonuria and some aspects of emotional development. Eur F Pediatr 1994;153:832-5.
34 Weglage J, Funders B, Ullrich K, Rupp A, Schmidt E. Psychosocial aspects of phenylketonuria. Eur $\mathcal{f}$ Pediatr chosocial aspects of phen

35 Holler KA, Fennell EB, Crosson B, Boggs SR, Mickle JP. Neuropsychological and adaptive functioning in younger versus older children shunted for early hydrocephalus. Child Neuropsychology 1995;1:6373

36 Thomasgard M, Metz WP, Edelbrock C, Shonkoff JP. Parent-child relationship disorders. 1. Parental overprotection and the development of the parent protection scale. $\mathcal{F}$ Dev Behav Pediatr 1995;16:244-50.

\section{The limping child}

Among the complaints that ring alarm bells in paediatricians' heads, back pain and a limp must come high on the list. The first prospective study of children presenting with a limp has been reported from Edinburgh (SU Fischer and TF Beattie. Fournal of Bone and Foint Surgery [Br] 1999;81-B:1029-34).

In the first six months of 1996, 244 children aged 1-14 years presented to the accident and emergency department of the Royal Hospital for Sick Children with a limp and no history of trauma. One child was excluded from analysis because of inadequate records. These children represented $0.18 \%$ of attendances and $63 \%$ of them were boys. Their median age was 4.35 years. About one third presented on the day of onset of the limp and $85 \%$ within a week of onset. A diagnosis was not made in 72 children (30\%). The most common final diagnoses were transient synovitis (23\%), irritable hip $(16 \%)$, and soft tissue injury or muscular strain (16\%). Perthes' disease, osteomyelitis, and slipped femoral capital epiphysis occurred in five, four, and one of the 243 patients. There is no mention of non-accidental injury.

Assessment included full clinical examination and usually full blood count and erythrocyte sedimentation rate (ESR). If the problem appeared to be in the hip, ultrasonography was performed by a consultant radiologist; $x$ rays were obtained as clinically indicated. After making a working diagnosis, $20 \%$ of children were discharged without follow up, $57 \%$ were followed up in the accident and emergency department, $12 \%$ were referred for speciality follow up, and $12 \%$ were admitted to hospital. A diagnosis was missed on first assessment in three children: two developed osteomyelitis but neither of them had had the full blood count and ESR required by protocol, another child had Langerhans' cell histiocytosis diagnosed radiologically after he had left the department.

With careful assessment in the emergency department most children presenting with a limp do not need to be admitted to hospital.

ARCHIVIST 